\title{
Inside a 3D simulation: Realism, dramatism and challenge in the development of students' teacher digital competence
}

\author{
Juan González-Martínez \\ Universitat de Girona \\ Mar Camacho Martí, Mercè Gisbert Cervera \\ Universitat Rovira i Virgili
}

\begin{abstract}
The universalisation of immersive technologies and digital 3D environments has enabled simulated experiences to be created in various contexts, one of which is education. These environments have immense potential for, for example, generating immersive situations in which students can experience real learning. Although realism, dramatism and challenge have been little explored in the field of education, they are increasingly viewed as interesting conditions to be satisfied when simulations aimed at ensuring meaningful learning in the virtual world are designed. This article reflects on these three qualities in a simulation experience for initial teacher training conducted under the Simul@b project, the main objective of which was to design, implement and evaluate a 3D simulations laboratory for developing teacher digital competence among primary and secondary schoolteachers. The results of this experience show that simulation in 3D environments is a productive strategy with enormous potential. Moreover, these environments enable the creation of realistic scenarios that allow teaching competences to be developed and whose simulation has a positive impact on learning.
\end{abstract}

\section{Introduction}

Simulation as a training strategy is without doubt an important ally in the skills acquisition process. It has been extensively used, for example, in medical studies (Alinier, 2007; Paige \& Morin, 2013; Rogers, 2011). The traditionally high costs involved (Kneebone, Nestel, Vincent, \& Darzi, 2007) are fully justified when they help to ensure that students have the opportunity to practice high-risk skills on a small scale and in controlled environments, extending results and minimising risks (Roberts, Warda, Garbutt, \& Curry, 2014). Fully justified in the medical field, simulation can also be applied to a multitude of equivalent contexts beyond the training of healthcare professionals.

Simulation-based learning strategies enable students to become more technically efficient, to receive direct support from experts as they acquire competences and to engage in contextualised learning in authentic professional situations. In addition, they also impact on students' learning of the emotional component (Kneebone et al., 2007). A priori ideal scenarios for developing significant learning are therefore presented. When simulations are discussed, it is common to begin by making far-reaching assertions about the significance of the learning, the direct application of this learning to professional practice, the authenticity of the learning context in comparison with the real world, and the validity of the transferability of the knowledge learned (Norman, Dore, \& Grierson, 2012).

However, it is also clear that simulations have not been widely used in educational contexts beyond medical studies (Park, Kim, \& Sohn, 2011). This surely represents a significant waste of opportunity when it comes to achieving important learning in all professional fields. Such under-exploitation is probably caused by the high overall cost of the simulations that we mentioned previously. In fact, in the teacher training context, simulations could account for the following special affordances: students learn in a safe environment, avoiding unachievable risks in the early stages of learning (Palés Argullós \& Gomar Sancho, 2010); the time needed for learning is shortened, so the learning curve is much more favourable (Vazquez-Mata \& GuillametLloveras, 2009); it is possible to make mistakes with no consequences, which has an immense impact on learning (Ziv \& Berkenstadt, 2008); the post-simulation debriefing is much more rewarding than it is when using other methodological strategies (Saiz Linares \& Susinos Rada, 2014); the learning experience is much more motivating and transferable to reality (Norman et al., 2012). As a consequence, it can be considered that 
simulations can constitute an interesting value for educational purposes and for experiencing different teacher training settings.

Moreover, with a different financial investment the generalisation of immersive technologies and 3D digital environments (Esteve-González, González Martínez, Gisbert Cervera, \& Cela-Ranilla, 2017) has enabled the creation of simulated experiences in a multitude of contexts. It is easy to begin documenting applications of these learning strategies in contexts such as education (Park et al., 2011) and business administration (Cornacchione, 2012) and, irrespective of the field of knowledge in question, to find studies that link simulations to constructivist or constructional approaches (Chittaro \& Ranon, 2007; Crookall, 2012).

Moreover, 3D simulation environments are viewed as having enormous potential (Dalgarno, 2002; Dalgarno \& Lee, 2010; De Freitas, Rebolledo-Mendez, Liarokapis, Magoulas, \& Poulovassilis, 2010; Rogers, 2011) for, for example, generating immersive situations, which are especially interesting from the simulation perspective. Almost a fifth of the experiences using virtual 3D environments are devoted to exploiting the possibilities offered by these environments for the simulation of educational situations (Reisoglu, Topu, Yilmaz, Karakus Yilmaz, \& Goktas, 2017).

Beyond general approaches, however, we know little about how traditional simulation properties work in 3D environments. Most authors, who are focused on face-to-face simulations in the context of medical education, assert that simulation is more effective for learning purposes the more realistic and dramatic it is and the more challenging it is for the students. Indeed, studies of realism (Alinier, 2010; Norman et al., 2012; Paige \& Morin, 2013; Virzi, 1989), dramatism (Alinier, 2007; Schank, 1997) and challenge (Kirlik, 2010; Nielsen \& Harder, 2013; Rudolph, Simon, \& Raemer, 2007) firmly underline the importance of designing simulations that take into account these three conditions in order to ensure that significant learning is achieved. However, little is known about the impact of realism, dramatism and challenge on 3D simulations in the educational environment. For these reasons we reflect on these three qualities by analysing an initial teacher training 3D simulation experience conducted in the context of the Simul@b project. The main objective of this project was to design, implement and evaluate a 3D simulations laboratory aimed at developing teacher digital competence among infant and primary schoolteachers.

\section{Conceptual framework}

As we mentioned in our Introduction, simulation has been extensively used in face-to-face experiments in the medical field, with the consequential use of material and human resources (Alinier, 2007). The medical training context should therefore be considered one of the main theoretical references for determining the effects of simulation on learning. There is also a great deal of consensus in recognising that the three most important conditions for ensuring that the simulation is effective are realism, dramatism and challenge (in that order) because of their strong contribution to the relevance of the learning activities (Kneebone et al., 2007; Maran \& Glavin, 2003; Roberts et al., 2014). Below we analyse the effects of these three conditions.

\section{Realism}

Realism may be defined as the learning strategies' degree of fidelity with the environment they aim to represent (Alessi, 1988; Cornacchione, 2012). The significance of realism is supported in the literature by evidence on its contribution to learning of quality (Allen, Otto, \& Hoffman, 2004). In general, participants in simulated experiences systematically relate the level of realism to the quality of their learning experience (Backlund et al., 2009). Consequently, this condition is considered to be one of the main contributors to the quality of the simulation (Gredler, 2004).

However, when we discuss realism we are not always referring to identical conditions for the simulation. In fact, it is common in the literature to find there is a distinction between two important lower order concepts: functional realism (physical realism or engineering realism) and psychological realism (Dahl, Alsos, \& Svanæs 2010; Maran \& Glavin, 2003; Norman et al., 2012; Paige \& Morin, 2013). Functional realism refers to the 
degree to which the simulation environment replicates the physical characteristics of the real environment in which a task is performed (Virzi, 1989). Psychological realism, on the other hand, refers to the degree to which the proposed learning tasks replicate those required in the professional situations for which the students are being trained (Maran \& Glavin, 2003; Norman et al., 2012). Some authors (Paige \& Morin, 2013) have also introduced a third type of realism - conceptual realism - which refers to the need for conceptual coherence in the range of information made available to the learner and is especially important in clinical simulations (Dieckmann, Manser, Wehner, \& Rall, 2007; Paige \& Morin, 2013; Rudolph et al., 2007). Conceptual realism is generally included within the concept of psychological realism.

With regard to the relative importance of these concepts, the literature recommends that minimum conditions should be guaranteed to ensure functional realism (i.e., the physical conditions should guarantee authenticity of the simulated environment) but that priority should be given to achieving a high degree of psychological realism (Maran \& Glavin, 2003; Norman et al., 2012). It is the students' engagement with the tasks they need to perform and the quality of their performance rather than the arrangement of the material elements that ensure that the experience is realistic (Paige \& Morin, 2013). Many authors therefore assert that the concept of psychological realism is in fact task realism (Dahl et al., 2010) and thus attempt to focus on the tasks more than the setting due to their importance for the learning experience.

According to Dahl et al. (2010), important elements underlying the concept of realism are:

- the concept of realism itself (understood in its dual dimension)

- acceptance by the user of the simulated situation

- effectiveness in terms of knowledge transfer

- the configuration of realism and its relation to dramatism

- process iterativity (to ensure learning is achieved).

In summary, these elements should enable students, preferably in the initial phases of the simulation, to experience the suspension of disbelief (Alinier, 2010) that will help them to perform the role required to carry out the simulation.

\section{Dramatism}

In its varied and disaggregated forms and for the reasons we have just mentioned, dramatism is often included within the concept of realism, or within the concept of cueing (the instructions students receive to conduct their learning experience) (Alinier, 2010; Paige \& Morin, 2013; Schank, 1997).

When applied to simulation situations, dramatism generally involves formulating the experience as a theatrical production that creates scenarios and situations with a highly dramatic component (paying special attention to script, performance and production); considers follow-ups for each simulation situation that enable the evolution of the cases to be observed in all their complexity; and establishes starring roles for experts, players, and participating professionals that ensure the appropriate development of the story inherent to the simulation (Schank, 1997). In this context, the idea that the script is a key component is easily traced to multiple authors, who recommend that it should be formulated in the most open and modular way possible so that it may comprise the most evolutions of authentically simulated simulations as possible (Alinier, 2010).

Finally, as we have already mentioned, dramatism is sometimes focused on the concept of cueing, that is, the instructions the student receives explicitly at the beginning of the simulation, or indirectly during the simulation, in the form of clues, hints or complementary expert advice, etc. The above observations contribute decisively to the concept of dramatism and, therefore, to improvements in the student's learning experience (Alessi, 1988; Dieckmann et al., 2007; Paige \& Morin, 2013). 


\section{Challenge}

In medical simulations, a challenge component has also been shown to contribute, implicitly or explicitly, to improvements in the student's learning experience. This often involves a competitive element that challenges the student. However, in simulated clinical practice, the very idea of attempting to save a patient often becomes an intrinsic challenge that renders it unnecessary to incorporate an explicit challenge into the learning situation. In both cases, challenge motivates the student to improve his or her performance (Kirlik, 2010).

Accepting a learning situation as a challenge means considering several important elements that may act together or separately tolerating the practice up to the limits of one's competence, appreciating the feedback one receives during the learning experience, having a propensity for self-reflection, having the ability to correct one's mistakes and to repeat actions, learning from one's mistakes, and tolerating being in situations that are both out of control and outside one's control (Rudolph, Raemer, \& Simon, 2014). These are the conditions that we could say increase the potential offered by the challenge allied to the learning experience. However, in many cases the challenge should be presented with caution so as not to create distressful situations for the students (Nielsen \& Harder, 2013).

\section{Simulated experience}

This experience is part of Simul@b, a four-year research and development project (2014-2017) led by the Universitat Rovira i Virgili. Its main objective was to design, implement and evaluate a 3D simulations laboratory for developing teacher digital competence for primary and secondary schoolteachers and determine which structural and functional characteristics of a $3 \mathrm{D}$ simulations laboratory could be helpful for this purpose.

The project arose from the need to ensure that pre-service schoolteachers acquire teacher digital competence (Esteve Mon, Adell Segura, \& Gisbert Cervera, 2014; Gisbert Cervera, González Martínez, \& Esteve Mon, 2016). To achieve this, and as a result of the progress made at the university in the use of 3D simulation environments for the acquisition of core competences (Cela Ranilla et al., 2011), a proposal was put forward to allow 70 second-year students in the Bachelor of Infant Education and Bachelor of Primary Education at the Universitat Rovira i Virgili, in the Bachelor in Primary Education at the Universitat de Lleida and in the Bachelor of Teaching and Learning (Early childhood and Primary) at the Universitat d'Andorra to participate in a simulation experience aimed at developing teacher digital competence (Esteve Mon et al., 2014).

The experience described below is a component of the implementation phase for a 3D simulation environment prototype that aims to exhaustively evaluate variables fundamentally related to the characteristics assumed to be used by 3D simulation in training processes (Atkins, 2009; De Freitas et al., 2010). During this phase, the validity criteria taken into account were construct validity, usability and practicality, and the discussion groups formed the data collection and analysis methods. Taking realism, dramatism and challenge as analysis variables, the research questions for this experience were:

- Did the 3D simulation enable you to immerse yourself into the reality of a school?

- Did the activities conducted in the 3D environment place you in the role of a teacher and enable you to perform the functions of a teacher?

- Did the setting for the activities allow you to immerse yourself in the story and let you believe you were a real teacher?

- Did the context of the simulation presented in this experience provide you with a challenge that motivated you?

Following a series of guidelines, the students participated in this collaborative simulation experience autonomously and asynchronously using OpenSim, a free preconfigured 3D simulation environment in which they were asked to develop a learning strategy based on Gisbert Cervera, González Martínez, \& Esteve Mon's (2016) four dimensions of the first level of performance of teacher digital competence: didactic, curricular and 
methodological; planning, organisation and management of digital technological spaces and resources; relational, ethical and safety; and personal and professional.

Because of the intrinsic limitations of OpenSim, the simulated sequence was based entirely on the tasks involved in teaching and teacher digital competence that do not require the presence of pupils in the classroom, that is, preparing lesson plans, designing and developing digital teaching materials, and career management. Through these tasks, students were encouraged to critically reflect and provide insights on aspects related to teacher digital competence, such as their role as future teachers, the use of a personal learning environment to craft teachers' professional identity, the new conceptualisations of learning spaces, or the ethical issues regarding the use of digital technologies in education. In order to carry out these tasks, 3D simulation activities included the creation of avatars, a deep knowledge of the virtual laboratory as a learning space, the creation and sharing of videos and other digital resources and the participation in in-world chats. All the activities were gathered in a student's portfolio.

\section{Methods}

The study, which is purely qualitative in nature (Bisquerra Alzina, 2004), analyses the importance of realism, dramatism and challenge in 3D simulations in the educational context. From a qualitative methodological approach, the study was conducted on completion of the OpenSim simulation experience in which student teachers were asked to develop a learning strategy related to the first level of performance of teacher digital competence. Linked to the research questions stated before, its main goals were to:

- $\quad$ analyse the participants' opinions on the relationship between the simulation and the school context

- identify which tasks carried out at school the participants identify most with the teaching profession

- determine how the dramatic elements impact on the participants' experience

- determine how the students assessed the challenge presented by the simulation.

This study employed qualitative data collection tools, namely, analysis of information gathered from discussion groups. On completion of the experience, the students were invited to participate in three focus groups (one for each participating university) held during the week of 19-23 December 2016. These groups, which comprised a total of 69 participants and were moderated by an expert researcher from each participating university, are the main source for the data collected for this study. To conduct the discussion groups, we used semi-structured qualitative interviews comprising questions related to the objectives of the study and the analysis variables selected: functional realism, psychological realism, dramatism and challenge (see Table 2).

The recordings of these discussion groups were transcribed into text format and imported into Atlas.Ti, a program for analysing qualitative data. These data were codified and, after a review of the literature, the following categories were created (see Table 1). 
Table 1

Codebook: categories and subcategories

\begin{tabular}{lll}
\hline Categories & Subcategories & \\
\hline \multirow{4}{*}{ Realism (R) } & Functional Realism (FR) & $\begin{array}{l}\text { Implication (FR_IMP); Simulation (FR_SIM) } \\
\text { Representation (FR_RP) } \\
\text { Learning Experience Situation (FR_LES) }\end{array}$ \\
\cline { 2 - 3 } & Psychological Realism (PR) & $\begin{array}{l}\text { Teaching Profession (PR_TP) } \\
\text { Digital Teacher Competence (PR_DTC) } \\
\text { Advanced Competence (PR_AC) } \\
\text { Learning Self-Perception (PR_LSP) }\end{array}$ \\
\hline \multirow{5}{*}{ Dramatism (DR) } & & \\
& Simulation (DR_SIM) & \\
& Immersion (DR_IM) & \\
& Identification (DR_ID) & \\
Challenge (CH) & Competitiveness (CH_C) & \\
& Risk (CH_R) & \\
& Reflection (CH_RF) & \\
& Correction (CH_COR) & \\
& Motivation (CH_MOT) & \\
&
\end{tabular}

The coded variables were organised in categories reflecting their relevance to the research questions. The aim was to enable responses to the following crossing of variables, indicators and research questions, which guided both the analysis and the presentation of the results (see Table 2).

Table 2

Variables, indicators and research questions

\begin{tabular}{clll}
\hline Variable & \multicolumn{1}{c}{ Indicator } & \multicolumn{1}{c}{ Research questions } & \multicolumn{1}{c}{ Objectives } \\
\hline Realism & $\begin{array}{l}\text { Functional } \\
\text { Realism }\end{array}$ & $\begin{array}{l}\text { Did the 3D simulation enable you } \\
\text { to immerse yourself into the } \\
\text { reality of a school? }\end{array}$ & $\begin{array}{l}\text { Analyse the participants } \\
\text { opinions on the relationship } \\
\text { between the simulation and the } \\
\text { school context. }\end{array}$ \\
\cline { 2 - 4 } & $\begin{array}{lll}\text { Psychological } \\
\text { Realism }\end{array}$ & $\begin{array}{l}\text { Did the activities conducted in } \\
\text { the 3D environment place you in } \\
\text { the role of a teacher and enable } \\
\text { you to perform the functions of a } \\
\text { teacher? }\end{array}$ & $\begin{array}{l}\text { Identify which tasks carried out } \\
\text { at school the participants identify } \\
\text { most with the teaching } \\
\text { profession. }\end{array}$ \\
& $\begin{array}{l}\text { Did the setting for the activities } \\
\text { allow you to immerse yourself in } \\
\text { the story and let you believe you } \\
\text { were a real teacher? }\end{array}$ & $\begin{array}{l}\text { Determine how the dramatic } \\
\text { elements impact on the } \\
\text { participants' experience. }\end{array}$ \\
& $\begin{array}{l}\text { Did the context of the simulation } \\
\text { presented in this experience } \\
\text { provide you with a challenge that } \\
\text { motivated you? }\end{array}$ & $\begin{array}{l}\text { Determine how the students } \\
\text { assessed the challenge presented } \\
\text { bramatism }\end{array}$ \\
& & & \\
\hline
\end{tabular}

\section{Analysis of the results}

To simplify the presentation of our results, we return to the initial research questions and present the data we collected by analysing the transcripts of the focus groups. For a complete overview of the main findings of the analysis, firstly of all, we provide a synthesis (answering every research question) and then a deep analysis with details of the different opinions and concepts that emerged. As far as possible, we illustrate each of the statements with fragments of the discussion groups that have been considered relevant. 


\section{Functional realism: Did the 3D simulation enable you to immerse yourself into the reality of a school?}

Generally speaking, when we predesigned the physical aspects of the school represented in the simulation our idea was to create a hyper-attributed scenario where the students would encounter many of the situations they would find in the average real school. We then tried to combine this scenario with a realistic and faithful representation of the elements that characterise a school. This led to two important assessments made in relation to functional realism. On the one hand, the participants recognised that the virtual environment was a faithful representation of what they expect to find in a real school:

(Universitat Rovira i Virgili [URV]. 02:05) Well, yes, it did look like a real school. It did look like a real school because there were different sections, the head teacher's office, the music room, the laboratory and the classrooms. I think so, yes.

On the other hand, the feeling that this was an ideal school in terms of available resources clearly clashed with the sense of a realistic virtual world:

(Universitat de Lleida [UdL]. 01:41) The virtual world and the real world are not similar because in the real world we don't have so many material or financial resources.

(URV. 02:30) I don't think it reflects a real school because it should be more traditional and not have such innovative classrooms. It looks more like a school of the future.

In general, the participants believed that having optimal conditions for managing resources limited rather than extended their learning opportunities:

(UdL. 04:13) Perhaps it would have been more useful for us if we had had few resources and been able to manage them because in that way you adapt to what you actually have [money]. Because later on, in real life, that's what you're faced with [as a teacher].

This appears to confirm that simulations, even in virtual scenarios, require authentic, non-idealised representations since the suspension of disbelief required for the learning experience was not achieved.

\section{Psychological realism: Did the activities conducted in the 3D environment place you in the role of a teacher and enable you to perform the functions of a teacher?}

We also found a mixture of positions regarding the similarity between the proposed tasks and those the participants expect to perform in their real professional careers. There was a general feeling that the tasks the participants were asked to perform were important as far as a teacher's real functions were concerned:

(URV. 05:51) Yes, I think so (...) For example, for activity 2 when we were deciding how to arrange the classroom, we first had to think as teachers to find out which things we could use with the kids and how we could use them.

However, there was a much more generalised belief that the activities did not correspond exactly to the functions a real teacher has to perform, as if planning lessons, managing and designing teaching materials were tangential tasks to the actual teaching that really characterises the teaching profession:

(UdL. 06:00) What we had to do was to create a classroom (our perfect classroom) but I couldn't put myself in the shoes of a teacher or a teacher's functions because all I had to do was create the classroom. Though I was able to imagine what I would have done with all the resources and materials I had. I just played the part of a person who created her perfect classroom. 
The participants' assessments of psychological realism were different when they discussed teacher digital competence since on this point the proposed tasks were generally viewed as being consistent with the development of this competence. As their perspective changed, so did their assessment of the experience, which they now considered to be more realistic and to have a greater impact on their learning:

(Universitat d'Andorra [UdA]. 2:37) Yes, I think we've got close to the role of a teacher because we had to create a virtual environment, use resources and create them ourselves to enable the kids and their parents to access them; for example, we had to create a web page, etc.

(URV. 15:37) As a teacher you need to know how to use digital resources well so, yes, it's strongly related to teacher digital competence (...). For activity 2 you also had to know how to manage the environment with the innovative features we had in the storeroom and to know how to use them as a teacher in front of the class.

This more positive assessment of the realism of the experience from the perspective of teacher digital competence led the participants to regard the impact they believe the experience had had on the development of their skills as positive. The general belief, therefore, was that the simulation helped them to improve their competences:

(UdL. 5:41) I think that all the activities in the project are focused on our digital competence because you're using something new and you've got to learn and work it out. Obviously, you do get help from the rest of the group but at the same time you've got to do your bit and teach yourself and find the tools and resources you can use and that are best for you.

There was therefore a clear perception of self-learning in most cases:

(UdL. 18:29) I think that the Simul@b experience is very good if what it teaches you or what you learn from it is something that you don't know rather than something you've already worked on in other subjects at the university, such as creating a web page.

However, in other cases, the participants felt that they did not make full use of the experience (perhaps because they felt they were working on the most basic and most technical levels of the competence and did not go deeply enough into them):

(URV. 16:15) (Regarding the tasks) The ones we did were about creating a Twitter or Facebook account, etc., .... we already know all that.

In conclusion, we do not have a convincing assessment on the psychological realism of this simulated experience. On the one hand, it seems that the participants did not perceive their experience as being very realistic, especially when we take their expectations into account since they thought the tasks would be linked more to actual teaching and less to the other functions teachers have to perform. In this sense, we could say that the simulation failed to suspend their disbelief and so did not ensure that acceptable levels of realism were reached. On the other hand, when the participants considered the simulation from the perspective of teacher digital competence, however, it appears that they did think the experience was suitable and useful and that it had a positive impact on their own teacher training.

\section{Dramatism: Did the setting for the activities allow you to immerse yourself in the story and let you believe you were a real teacher?}

With regard to dramatism, the focus groups brought up everything related to the concept of cueing that we mentioned earlier. As the simulation did not include simulated actors or interaction with bots, the participants paid special attention to the script and to their instructions as the elements that would enable them (or not enable them) to enter the environment. In general, the assessments made by the three groups were very positive. The instructions they received both at the beginning and during the experience were evaluated highly: 
(URV. 30: 06) Yes, I think so. It set the scene very well. It was a specific situation (...). Also, the fact that you had your own physical classroom made you immerse yourself even more into the situation.

(UdL. 24:03) I think the way you set up the activities was very good. I mean you didn't just say "do that", you found information; I think everything you created in the virtual environment was very good.

In particular, the participants appreciated the fact that the instructions and the scenario encouraged them to believe in the situation and to accept the simulation as authentic.

The assessment from one participating university was completely negative, however. Some of these participants even censured a certain rush in providing them with instructions that prevented them from getting fully involved due to a lack of information:

(UdA. 6:43) I don't think the instructions for the first part were very good and I think some information was missing (...) because it was all a bit rushed and all of a sudden we didn't know what we had to do or how to do it. Perhaps we should have more time at the beginning so that we could be clearer on what to do all the way through? Yes, explain it in greater detail. Do you agree? Yes, totally.

This difference of opinion among the participants had already been perceived by some students before the focus groups were set up and was even brought up spontaneously by one of them. On a related issue, the participants from another university discussed the negative perception of some of their colleagues:

(URV. 27:53) I think so. The instructions placed you in a situation. Perhaps the other universities interpreted it in a different way (...) The instructions had good explanations.

This illustrates how the instructions (which were the same for all participants and were provided by the same researchers in equivalent sessions to all three groups) were interpreted differently by different groups. Dramatism of the experience was therefore perceived in very different ways: those who received the instructions they needed to immerse themselves in the simulation thought the script they were given was suitable. Others thought the opposite was true, or at least they may have understood what we wanted from them and their simulation but thought that the instructions they were given did not enable them to immerse themselves in the story:

(UdL. 27:48) Yes, I did understand what you wanted us to, that we should work as teachers rather than as students, (...) that you wanted us to feel like teachers. Maybe you didn't achieve that but we understood that is what you wanted us to do.

\section{Challenge: Did the context of the simulation presented in this experience provide you with a challenge that motivated you?}

Finally, we will discuss challenge, the third of the simulation qualities. In the simulation experience conducted for this study, the idea of challenge was based on a competition between the three participating groups to receive an excellence award for the quality of the tasks performed.

However, the very idea of holding a competition at all was evaluated negatively, which fully illustrates the extent to which making the competition the core challenge was a mistake:

(UdL. 35:16) Since we have to put ourselves in the shoes of teachers, I think that competition in the classroom or in the school is ok only up to a certain point because you can't go thinking that you're the best. 
(URV. 37:50) I didn't compete with my colleagues at all; in fact, I did the opposite. I learned from them because there were a lot of things I didn't know how to do and I learned by interacting with my colleagues. I'm happy to have taken part.

It was even suggested that the level of competition would have been more intense if it had been arranged between students of the same university rather than between inter-university groups:

(UdA. 9:47) It would be more competitive, and more motivating, if we had competed with the other universities. It would have been better and communication would have been easier and more direct. We would have had a more dynamic group. It's more complicated when the members of the group are from different universities because at certain times they can't chat or they're working.

In general, the experience was both motivating and demotivating in equal measure: some felt that they had learned from it, whereas others felt that they had not:

(UdA. 9:31) I think the project's fine; it's entertaining if it's dynamic and well explained, and if you've got time to spend on it (...) but otherwise it's quite complicated. I quite liked doing it.

(UdA. 8:57) They didn't motivate us because we didn't hear anything about the award and they didn't inform us, nobody told us about it. [DR_IM; CH_C] (9:20) Perhaps what motivated us was passing the subject (laughter).

The challenge dimension was perhaps the least successful one because the excellence award, which was intended to be the main source of motivation and to encourage competition, was precisely the part of the experience that was least well understood by the students. Motivation for this aspect of the experience was therefore low, and the other aspects were badly affected because of it.

\section{Discussion and conclusions}

The data collected in this study should enable us to confirm whether 3D simulation environments can be used to generate high-quality simulated learning situations for the training of future teachers, which was the aim of this study. This will depend on how far these environments can provide dramatic, realistic situations that also contain a challenge component. We began with the idea that simulation involves a safe and protected environment in which competences can be acquired in small doses without incurring any of the risks involved in deploying those competences in the real world. This is very interesting as an initial phase of learning. We also began with the knowledge that $3 \mathrm{D}$ environments have great potential for reducing the costs associated with learning strategies (Kneebone et al., 2007; Norman et al., 2012; Roberts et al., 2014). All this should be enabled by simulated sequences with high doses of functional and psychological realism (Dahl et al., 2010; Maran \& Glavin, 2003), dramatism (Alinier, 2010; Paige \& Morin, 2013) and challenge (Nielsen \& Harder, 2013; Rudolph et al., 2007).

We can conclude that in general terms simulation in 3D environments is confirmed as a productive strategy with great potential. There is no doubt, for example, that immersive environments have great potential for recreating authentic learning scenarios (functional realism). In our study we decided to strike a balance between the authenticity of the schools encountered by the students on entering the virtual world and the high provision of technological resources (more than are currently available in the average school). Although this produced a certain disagreement among the participants because of its contrast with the actual situation faced by schools today (especially those with limited resources), it was not generally criticised by the students. We can conclude, therefore, that $3 \mathrm{D}$ simulation environments enable realistic scenarios to be created in which teaching competences can be developed. 
Our conclusions are somewhat different when it comes to psychological realism, however. Our students valued the experience differently when they were asked about teacher training in general from when they were asked about the acquisition of teacher digital competence. With regard to the former, the limitations of the immersive environment, which does not allow the participants to interact massively with controlled avatars that simulate being students (or with bots), affected how the participants assessed which functions should be developed in the environment. This in turn affected the psychological realism of the simulation. However, with regard to the acquisition of teacher digital competence, the students had a stronger perception of psychological realism and felt that what they were simulating was faithful to reality (Norman et al., 2012). More importantly, they also felt that the simulation had a positive and significant impact on their learning (Backlund et al., 2009; Gredler, 2004).

Now we turn to the question of dramatism, which has much in common with the above. On the one hand, the participants' assessments were inconsistent because some participants felt that the script for the experience was well prepared whereas others had completely the opposite opinion. On the other hand, we wonder how much of this inconsistency is down to the students' expectations that they were going to participate in a 3D simulation in which they "were going to be teachers" (and expected to interact with students who, subsequently, did not turn up) rather than participate in the actual simulation, which involved every aspect of teacher digital competence that does not involve direct interaction with students. This illustrates how dramatism, a variable we have been unable to fully recreate, can also affect psychological realism (Paige \& Morin, 2013).

Finally, we turn once again to the issue of challenge. Undoubtedly, challenge is the dimension we have least been able to recreate productively. When we began our study, we discussed how in medical education the very challenge represented by saving or healing a patient becomes an intrinsic and motivating challenge that stimulates the learning process (Kirlik, 2010). In comparison, the tasks associated with teacher digital competence, as far we have conceived them in this experience, undoubtedly do not contain an equal amount of this intrinsic challenge component. For this reason, we proposed a competition that could provide students with an extrinsic challenge when conducting the simulation. Although this idea of a competition was not considered negatively by everyone, it certainly did not function as the stimulus it was intended to be, or at least that we generally find in the most productive simulations in terms of learning (Nielsen \& Harder, 2013; Rudolph et al., 2007). On the contrary, in fact: it actually produced a certain amount of unwanted distress and discomfort for the students (Rudolph et al., 2014) and so we must reconsider our use of this element in future simulations.

At this point, we can reflect on what the new lines of research that have been opened are; and we may also point out their implications in terms of educational policy and practice. In relation to the first question, we have seen how the three main characteristics of the simulation work in their application on multi-user virtual environments. This leads us to consider that these technological environments, despite their limitations and particularities, may be the appropriate scenario for teacher training settings based on digital simulation. However, we should continue to explore which learning experiences take more advantage of these situations; and we must also know more about the especially interesting characteristics of multi-user virtual environments and that makes them more suitable to teacher training simulations. Secondly, and according to the lessons learnt in the project, simulations appear to be a very interesting teacher training strategy. This encourages us to plan its use in our faculties, in order to achieve deeper, more complete and transferable learning experiences.

In summary, 3D simulation environments provide very interesting possibilities for teacher training simulation. They can be highly productive, and their cost is generally lower than other complex learning situations (such as actual simulation or supervised teaching practice) (Norman et al., 2012, Roberts et al., 2014). 3D simulation environments also enable us to recreate realistic and authentic learning situations that have a genuine impact on learning of quality (Backlund et al., 2009). However, we also need to recognise that we must analyse the dramatic and challenge elements of this experience further if we wish to make the most of all of its possibilities and bring them to fruition. 


\section{Acknowledgements}

This research is part of the project called Simul@b: a 3D simulation laboratory for the development of teaching digital competence, funded by the Spanish Ministry of Economy and Competitiveness and whose reference is EDU2013-42223-P.

\section{References}

Alessi, S. M. (1988). Fidelity in the design of instructional simulations. Journal of Computer-Based Instruction, 15(2), 40-47. Retrieved from https://dl.acm.org/citation.cfm?id=46756\&picked=prox

Alinier, G. (2007). Opening of an enhancing trainees' learning experiences through the Advanced Multiprofessional Simulation Training Facility at the University of Hertfordshire. British Journal of Anaesthetic and Recovery Nursing, 8(2), 22-27. https://doi.org/10.1017/S1742645607000125

Alinier, G. (2010). Developing high-fidelity health care simulation scenarios: A Guide for educators and professionals. Simulation \& Gaming, 42(1), 9-26. https://doi.org/10.1177/1046878109355683

Allen, B. S., Otto, R. G., \& Hoffman, B. (2004). Media as lived environments: The ecological perspective of educational technology. In D. H. Jonassen (Ed.), Handbook of research on educational communication and technology (2nd ed., pp. 215-242). Mahwah, NJ: Lawrence Erlbaum.

Backlund, P., Engstrm, H., Gustavsson, M., Johannesson, M., Lebram, M., \& Sjrs, E. (2009). SIDH: A gamebased architecture for a training simulator. International Journal of Computer Games Technology, 2009(1). https://doi.org/10.1155/2009/472672

Bisquerra Alzina, R. (2004). Metodología de la investigación educativa (2. ${ }^{a}$ edició) [Educational research methodology]. Madrid: La Muralla.

Cela Ranilla, J. M., Esteve, V., Marqués Molías, L., Gisbert Cervera, M., Arias, Í., Vaca, B. E., \& Samaniego, G. N. (2011).SIMUL@: 3D spaces to learn generic skills. A pilot study with education students. Paper presented at 6th International Conference on e-Learning, University of British Columbia, Canada.

Chittaro, L., \& Ranon, R. (2007). Web3D technologies in learning, education and training: Motivations, issues, opportunities. Computers and Education, 49(1), 3-18. https://doi.org/10.1016/j.compedu.2005.06.002

Cornacchione, E. B. (2012). Fidelity and game-based technology in management education. BAR - Brazilian Administration Review, 9(2), 147-167. https://doi.org/10.1590/S1807-76922012000200003

Crookall, D. (2012). The founding of modern simulation/gaming: S\&G and ISAGA four decades on. Simulation \& Gaming, 43(1), 5-14. https://doi.org/10.1177/1046878112437916

Dahl, Y., Alsos, O. A., \& Svanæs, D. (2010). Fidelity considerations for simulation-based usability assessments of mobile ICT for hospitals. International Journal of Human-Computer Interaction, 26(5), 445-476. https://doi.org/10.1080/10447311003719938

Dalgarno, B. (2002). The potential of 3D virtual learning environments: A constructivist analysis. Electronic Journal of Instructional Science and Technology (e-JIST), 5(2), 1-19. Retrieved from http://ascilite.org/archived-journals/e-jist/docs/Vol5 No2/dalgarno frame.html

Dalgarno, B., \& Lee, M. J. W. (2010). What are the learning affordances of 3-D virtual environments? British Journal of Educational Technology, 41(1), 10-32. https://doi.org/10.1111/j.1467-8535.2009.01038.x

De Freitas, S., Rebolledo-Mendez, G., Liarokapis, F., Magoulas, G., \& Poulovassilis, A. (2010). Learning as immersive experiences: Using the four-dimensional framework for designing and evaluating immersive learning experiences in a virtual world. British Journal of Educational Technology, 41(1), 69-85. https://doi.org/10.1111/j.1467-8535.2009.01024.x

Dieckmann, P., Manser, T., Wehner, T., \& Rall, M. (2007). Reality and fiction cues in medical patient simulation: An interview study with anesthesiologists. Journal of Cognitive Engineering and Decision Making, 1(2), 148-168. https://doi.org/10.1518/155534307X232820

Esteve Mon, F. M., Adell Segura, J., \& Gisbert Cervera, M. (2014). Diseño de un entorno 3D para el desarrollo de la competencia digital docente en estudiantes universitarios: Usabilidad, adecuación y percepción de utilidad [Design of 3D environment to develop pre-service teachers' digital competence: usability, adequacy and perceived usefulness]. Revista Latinoamericana de Tecnología Educativa RELATEC, 13(2), 35-47. Retrieved from http://relatec.unex.es/article/view/1443 
Esteve-González, V., González Martínez, J., Gisbert Cervera, M., \& Cela-Ranilla, J. (2017). La presencia social en entornos virtuales 3D: Reflexiones a partir de una experiencia en la universidad [Social presence in 3D virtual environments: Reflections upon a teaching experience in the university]. Pixel-Bit Revista de Medios Y Educacion, 50, 137-146. https://doi.org/10.12795/pixelbit.2017.i50.09

Gisbert Cervera, M., González Martínez, J., \& Esteve Mon, F. M. (2016). Competencia digital y competencia digital docente: Una panorámica sobre el estado de la cuestión [Students' and teachers' digital competence: An overview on research status]. Revista Interuniversitaria de Investigación En Tecnología Educativa, 0(Junio), 74-83. https://doi.org/10.6018/RIITE2016/257631

Gredler, M. E. (2004). Games and simulations and their relationships to learning. In D. H. Jonasen (Ed.), Handbook of research on educational communications and technology (2nd ed., pp. 571-581). Mahwah, NJ: Lawrence Erlbaum.

Kirlik, A. (2010). Brunswikian theory and method as a foundation for simulation-based research on clinical judgment. Simulation in Healthcare: Journal of the Society for Simulation in Healthcare, 5(5), $143-147$. https://doi.org/10.1097/SIH.0b013e3181f12f03

Kneebone, R. L., Nestel, D., Vincent, C., \& Darzi, A. (2007). Complexity, risk and simulation in learning procedural skills. Medical Education, 41(8), 808-814. https://doi.org/10.1111/j.1365-2923.2007.02799.x

Maran, N. J., \& Glavin, R. J. (2003). Low- to high-fidelity simulation - a continuum of medical education? Medical Education, 37(Suppl. 1), 22-28. https://doi.org/10.1046/j.1365-2923.37.s1.9.x

Nielsen, B., \& Harder, N. (2013). Causes of student anxiety during simulation: What the literature says. Clinical Simulation in Nursing, 9(11), e507-e512. https://doi.org/10.1016/j.ecns.2013.03.003

Norman, G., Dore, K., \& Grierson, L. (2012). The minimal relationship between simulation fidelity and transfer of learning. Medical Education, 46(7), 636-647. https://doi.org/10.1111/j.13652923.2012.04243.x

Paige, J. B., \& Morin, K. H. (2013). Simulation fidelity and cueing: A systematic review of the literature. Clinical Simulation in Nursing, 9(11), e481-e489. https://doi.org/10.1016/j.ecns.2013.01.001

Palés Argullós, J. L., \& Gomar Sancho, C. (2010). El uso de las simulaciones en educación médica [Simulation in medical education]. Education in the Knowledge Society (EKS), 11(2), 147-170. Retrieved from http://revistas.usal.es/ revistas trabajo/index.php/revistatesi/article/view/7075

Park, J., Kim, D. E., \& Sohn, M. H. (2011). 3D simulation technology as an effective instructional tool for enhancing spatial visualization skills in apparel design. International Journal of Technology and Design Education, 21(4), 505-517. https://doi.org/10.1007/s10798-010-9127-3

Reisoglu, I., Topu, B., Yilmaz, R., Karakus Yilmaz, T., \& Goktas, Y. (2017). 3D virtual learning environments in education: A meta-review. Asia Pacific Education Review, 18, 81-100. https://doi.org/10.1007/s12564-016-9467-0

Roberts, S. G., Warda, M., Garbutt, S., \& Curry, K. (2014). The use of high-fidelity simulation to teach cultural competence in the nursing curriculum. Journal of Professional Nursing, 30(3), 259-265. https://doi.org/10.1016/j.profnurs.2013.09.012

Rogers, L. (2011). Developing simulations in multi-user virtual environments to enhance healthcare education. British Journal of Educational Technology, 42(4), 608-615. https://doi.org/10.1111/j.14678535.2010.01057.x

Rudolph, J. W., Raemer, D. B., \& Simon, R. (2014). Establishing a safe container for learning in simulation. Simulation in Healthcare: Journal of the Society for Simulation in Healthcare, 9(6), 339-349. https://doi.org/10.1097/SIH.0000000000000047

Rudolph, J. W., Simon, R., \& Raemer, D. B. (2007). Which reality matters? Questions on the path to high engagement in healthcare simulation. Simulation in Healthcare: Journal of the Society for Simulation in Healthcare, 2(3), 161-163. https://doi.org/10.1097/SIH.0b013e31813d1035

Saiz Linares, Á., \& Susinos Rada, T. (2014). El desarrollo de profesionales reflexivos: Una experiencia en la formación inicial de médicos a través de simulación clínica [Development of reflective practitioners: An experience in preservice medical training through clinical simulation]. Revista de Docencia Universitária, 12(2), 453-476. https://doi.org/10.4995/redu.2014.5657

Schank, R. C. (1997). Virtual learning: A revolutionary approach to building a highly skilled workforce. New York, NY: McGraw Hill. 
Vázquez-Mata, G., \& Guillamet-Lloveras, A. (2009). El entrenamiento basado en la simulación como innovación imprescindible en la formación médica [Simulation-based training as an essential innovation for medical education]. Educación Médica, 12(3), 149-155. https://doi.org/10.4321/S157518132009000400004

Virzi, R. A. (1989). What can you learn from a low-fidelity prototype? In HFES (Ed.), Proceedings of the Human Factors and Ergonomics Society Annual Meeting (Vol. 33, pp. 224-228). https://doi.org/10.1177/154193128903300405

Ziv, A., \& Berkenstadt, H. (2008). La educación médica basada en simulaciones [Simulation-based medical education]. Jano: Medicina Y Humanidades, 1701, 42-45.

Corresponding author: Juan González-Martínez, juan.gonzalez@udg.edu

Australasian Journal of Educational Technology (C) 2019.

Please cite as: González-Martínez, J., Camacho Martí, M., \& Gisbert Cervera, M. (2019). Inside a 3D simulation: Realism, dramatism and challenge in the development of students' teacher digital competence. Australasian Journal of Educational Technology, 35(5), 1-14. https://doi.org/10.14742/ajet.3885 